\title{
Abordagem simbiótica entre TICs e física no ensino médio mediada por arduino
}

\section{Symbiotic approach between ICTs and physics in high school mediated by arduino}

\author{
R. B. SouzA ${ }^{* 1}$ \\ ${ }^{1}$ Escola Estadual Eduardo Milton da Silva
}

\begin{abstract}
Resumo
O presente trabalho consiste no relato de uma sequência didática desenhada de modo a despertar nos estudantes o interesse intrínseco pelo estudo através da valorização dos conhecimentos e métodos próprios da ciência, de maneira a desenvolver competências ligadas à cultura digital e capacitá-los a lidar de forma crítica e consciente com as tecnologias de informação e comunicação, assim como, em particular, ilustrar conceitos, termos e procedimentos típicos da Física. Destinada a alunos do $3^{\circ}$ ano do Ensino Médio, o trabalho foi executado como atividade complementar no espaço físico disponibilizado pela escola em sábados não letivos. Composta por 20 encontros de $2 \mathrm{~h}$ cada, todos os recursos tecnológicos que constituíram ferramentas de trabalho foram adquiridos com aportes oriundos do PROEMI, projeto do Governo Federal voltado ao desenvolvimento de atividades inovadoras no Ensino Médio. Ao final das análises, constatou-se nítida evolução conceitual nos alunos que dele participaram, para além da aquisição de algumas habilidades técnicas
\end{abstract}

Palavras-chave: Tecnologias de Informação e Comunicação. Arduino. Física. Relação simbiótica.

*renattobsouza@gmail.com 


\begin{abstract}
The present work consists in the report of a didactic sequence designed in order to arouse intrinsic interest in students for the study through the valorization of the knowledge and own methods of the science, aiming to develop competences linked to the digital culture and to enable them to deal in a critical and conscious way with information and communication technologies, as well as, in particular, illustrating concepts, terms and procedures typical of Physics. Aimed at students in the 3rd year of high school, the work was performed as a complementary activity in the physical space provided by the school on non-school Saturdays. Comprising 20 meetings of $2 \mathrm{~h}$ each, all the technological resources that constituted work tools were acquired with contributions from PROEMI, a Federal Government project aimed at developing innovative activities in high school. At the end of the analysis, a clear conceptual evolution was observed in the students who participated in it, besides the acquisition of some technical skills.
\end{abstract}

Keywords: Information and Communication Technologies. Arduino. Physics. Symbiotic relationship.

\title{
I. INTRODUÇÃO
}

Há, atualmente, ressonante consenso quanto à importância do emprego das tecnologias de informação e comunicação (TIC's) como elemento motivador nas aulas sobre Ciências Naturais, de um modo geral, mas em particular no ensino de Física. Com efeito, diversos trabalhos de pesquisa podem ser encontrados na literatura tratando desse assunto (Veronez et al, 2015; Lara et al, 2013; Pires e Veit, 2006).

Enquanto docentes preocupados em envolver os alunos em atividades dinâmicas no intento de tornar as aulas mais atraentes e propiciar tanto quanto possível a aprendizagem dos conceitos físicos abordados, fica deveras patente o fato de que o recurso a práticas experimentais visando à mera demonstração dos fenômenos físicos por si só não é suficiente para despertar o interesse intrínseco pelo estudo e pela aquisição do saber, requisitos tão caros a um bom desempenho escolar, diminuição da evasão e formação de indivíduos comprometidos a promover mudanças no meio onde vivem. Faz-se necessário exercitar a curiosidade intelectual, muitas vezes esquecida pela ausência de estímulo ao longo da trajetória escolar, desenvolver o gosto por resolver problemas, assumir o papel de sujeito ativo em uma sociedade carente de protagonistas e salientar a importância da análise crítica, da imaginação, da criatividade, e reconhecer a relevância das ciências e engenharias para o bem estar da humanidade.

Tendo em vista o significativo interesse demonstrado por muitos alunos com respeito a assuntos ligados à tecnologia, e considerando a premência em se chamar a atenção para a Ciência, especialmente a Física, enquanto conjunto de conhecimentos historicamente adquiridos que propiciam a capacidade de resolução de problemas e possibilitam a explicação de fenômenos naturais (BRASIL, 2017), foi erigido o seguinte problema: O que poderia ser feito dentro da escola que oportunizasse o diálogo e cooperação entre as duas áreas, a saber, 
entre a tão desejada (e necessária) tecnologia e a sumamente necessária (e não reconhecida) Ciência?

Como resposta a essa questão, buscou-se arquitetar um trabalho que utilizasse o Arduino, plataforma de computação física que pode interagir com o meio externo mediante software e hardware (MCROBERTS, 2011), como ferramenta através da qual seria possível abordar conceitos físicos ligados à eletricidade, magnetismo, termometria, entre outros, ao lado de tópicos de eletrônica e linguagem de programação, tudo isto vindo a calhar de maneira mais próxima com as competências gerais da BNCC (BRASIL, 2017, p. 9), a saber, a primeira, a segunda, a quarta e a quinta, respectivamente tratando da valorização e utilização da Ciência, criação de soluções tecnológicas com base em conhecimentos provenientes de diferentes áreas, utilização de linguagens digitais e compreensão de tecnologias digitais de informação e comunicação.

Diante disso, o principal objetivo do presente trabalho não foi outro senão criar e implementar uma sequência didática que oportunizasse o diálogo natural entre as TIC's e a Física por meio do Arduino. O sucesso da tarefa a que nos propomos inevitavelmente passou pela valorização e utilização do conhecimento científico (BRASIL, 2017, p. 9, 1), pelo estímulo ao exercício da curiosidade intelectual e criação de soluções tecnológicas (BRASIL, 2017, p. 9, 2), o uso da linguagem digital como forma de expressão (BRASIL, 2017, p. 9, 4), e pela compreensão, utilização e criação de tecnologias digitais de informação e comunicação de forma crítica, significativa, reflexiva e ética nas diversas práticas sociais (BRASIL, 2017, p. $9,5)$.

\section{Fundamentação TEÓRICA}

A forma como a sequência didática foi estruturada, assim como as ações levadas a cabo para promover o interesse dos alunos pelos conteúdos por ela abarcados, em grande medida se viu guiada pelos parâmetros pedagógicos apregoados pela Teoria da Aprendizagem Significativa, de David Ausubel (1978), e pelos trabalhos de Delizoicov e Angotti (1990) no âmbito dos Três Momentos Pedagógicos (3MP's).

No tocante ao conceito de aprendizagem significativa, proposto por Ausubel em sua teoria, mas também estudado por Marco Antônio Moreira, pode-se defini-lo assim:

É um conceito, uma ideia, uma proposição já existente na estrutura cognitiva, capaz de servir de ancoradouro a uma nova informação de modo que esta adquira, assim, significado para o indivíduo (i. e. que ele tenha condições de atribuir significados a essa informação). (MOREIRA, 2009. p. 8)

Dado que o conceito de estrutura cognitiva é aqui entendido como o conteúdo total e organização de ideias do indivíduo, a ocorrência da referida aprendizagem significativa demanda o relacionamento entre as novas informações, obtidas do ambiente, e aquelas as quais ele já dispõe. Em termos práticos, ao longo de toda a implementação da sequência didática lançamos mão dessa observação para viabilizar uma aprendizagem significativa não apenas de conteúdos novos com os quais os alunos paulatinamente iam entrando 
em contato, mas especialmente com aquelas informações que eventualmente tenham sido apreendidas mecanicamente (ou seja, sem a necessária ancoragem na estrutura cognitiva preexistente) durante as aulas regulares na disciplina de Física.

No que se refere aos 3MP's, Muenchen e Delizoicov (2014, p. 620) sucintamente os estruturam do modo seguinte:

Problematização inicial: apresentam-se questões ou situações reais que os alunos conhecem e presenciam e que estão envolvidas nos temas. Nesse momento pedagógico, os alunos são desafiados a expor o que pensam sobre as situações, a fim de que o professor possa ir conhecendo o que eles pensam. Para os autores, a finalidade desse momento é propiciar um distanciamento crítico do aluno ao se defrontar com as interpretações das situações propostas para discussão, e fazer com que ele sinta a necessidade da aquisição de outros conhecimentos que ainda não detém.

Organização do Conhecimento: momento em que, sob a orientação do professor, os conhecimentos de física necessários para a compreensão dos temas e da problematização inicial são estudados.

Aplicação do Conhecimento: momento que se destina a abordar sistematicamente o conhecimento incorporado pelo aluno, para analisar e interpretar tanto as situações iniciais que determinaram seu estudo quanto outras que, embora não estejam diretamente ligadas ao momento inicial, possam ser compreendidas pelo mesmo conhecimento.

No primeiro dos três momentos realiza-se a problematização inicial cujo principal objetivo é despertar nos alunos a necessidade de se apropriar de certo corpo de informações. Para tanto, são propostas questões ou situações reais capazes de lhes atiçar a curiosidade, após o que respostas às quais são solicitadas com base unicamente no conhecimento que têm sobre o assunto. Ao mesmo tempo, o professor encontra oportunidade de entrar em contato com os conhecimentos prévios de seus alunos, um elemento de crucial importância para a promoção de aprendizagem significativa, vez que servirão de ancoradouro para as novas informações (AUSUBEL, 1978). No segundo momento os conhecimentos científicos são sistematicamente estudados a fim de possibilitar a compreensão do tema bem como da problematização inicial (DELIZOICOV e ANGOTTI, 1990). Por fim, no terceiro momento haverá a aplicação do conhecimento científico incorporado pelo aluno visando à análise e compreensão da situação inicial a ele colocada, e de outras questões a serem propostas pelo professor - é natural que essas questões e os problemas colocados aos alunos nessa etapa apresentem grau de complexidade sensivelmente maior que aqueles ocasionalmente propostos no segundo momento, a fim de que surjam "[...] novos questionamentos, novas possibilidades de (re) criar a realidade, além de desconstruir a visão ingênua da mesma"(LYRA, 2013, p. 46). 


\section{Contexto escolar}

A escola em que o trabalho foi realizado é pública, de ordem estadual, localizando-se num município do interior de Minas Gerais. Contempla os ensinos fundamental e médio, sendo a única escola a ofertar este último nível na cidade, razão pela qual seu alunado reflete com fidelidade a diversidade de classes sociais que compõem a cidade, tendo inclusive expressivo número de procedentes de localidades rurais circunvizinhas.

Em razão da infraestrutura pedagógica deficiente, precária em muitos aspectos, como recursos laboratoriais insuficientes ao apoio das explanações teóricas, a utilização de componentes eletrônicos como o Arduino apenas se tornou possível com os recursos oriundos do programa do Governo Federal PROEMI (Programa Ensino Médio Inovador), através do qual a escola adquiriu placas de Arduino, protoboards, conectores, leds, resistores, e uma ampla gama de sensores, tais como de luminosidade, de temperatura, de fluxo hídrico, de umidade e de presença. Em razão da limitação imposta pela presença de outros projetos exigidos pelo programa, a quantidade de componentes comprada (algo em torno de R $\$$ $1500,00)$ foi suficiente para o atendimento de apenas 12 alunos, todos eles selecionados da $3^{a}$ série do Ensino Médio em razão de maturidade, anseios relativos a futuras profissões e compatibilidade com a grade curricular da disciplina. A seleção dos mesmos se pautou pelo interesse demonstrado em participar do projeto e pela afinidade que exibiam no tocante à área tecnológica

A cidade onde se encontra a escola carece de boas oportunidades de emprego, pelo que a maioria dos alunos, ao término do processo escolar, optam por migrar aos grandes centros, como Belo Horizonte, São Paulo e Rio de Janeiro. Parte significativa daqueles que deliberam ingressar no Ensino Superior imediatamente após se formarem o fazem a cursos como Direito, Engenharia Civil e licenciaturas, havendo, aparentemente, baixíssima demanda por áreas tecnológicas - embora necessite de um estudo pormenorizado, não seria disparate supor que esse pouco desejo em seguir uma carreira que envolva tecnologia e inovação está muito mais relacionado à quase ausência de divulgação do que a um desinteresse intrínseco pela área.

\section{Metodologia}

A sequência didática foi preparada prevendo-se 20 encontros semanais, realizados aos sábados - não exatamente sequenciais - entre os meses de março e novembro de 2018, de $2 \mathrm{~h}$ de duração cada, compondo-se de três etapas, desenhadas de maneira a aproximar-se da metodologia dos 3MP's. Na primeira delas houve uma conversa com o intuito de levantar as concepções prévias dos alunos a respeito do tema; a segunda se destinou à aquisição de conhecimentos e experiência com a função de sensores os mais variados por via da execução de pequenos projetos dispostos em material didático obtido na internet, assim como consolidação de conceitos físicos, entre os quais tensão elétrica, corrente, resistência elétrica, temperatura, associação de resistores, curto-circuito e circuitos elétricos de um modo geral; por fim, na última etapa os projetos finais de cada grupo foram desenvolvidos e apresentados. 


\section{IV.1. Desenvolvimento das atividades}

\section{IV.1.1 Etapa 1: problematização inicial}

\section{$1^{\circ}$ encontro}

Em consonância com os ditames da Teoria da Aprendizagem Significativa, na primeira etapa os conhecimentos prévios dos alunos sobre tópicos de elétrica e eletrônica foram levantados mediante uma discussão informal e amena visando deixá-los mais propensos a se expressarem. Constituindo a primeira das três etapas que compõem a sequência didática, esse encontro (de $2 \mathrm{~h}$ de duração) foi necessário para entender a estrutura de funcionamento de uma protoboard, placa com pinos interconectados sobre a qual grande parte dos circuitos seriam montados, e adquirir um contato inicial com alguns dos sensores e componentes constantes no arsenal de recursos, não sem antes que situações preliminares tivessem sido colocadas a fim de estimular os alunos a buscar conhecimentos mais profundos para o entendimento de determinadas questões.

\section{IV.1.2 Etapa 2: Organização do conhecimento}

Nesta etapa, constituída por 15 encontros, os alunos realizaram atividades práticas e teóricas envolvendo a montagem de projetos com o Arduino e a elaboração de programas por via da linguagem de programação C. Como se observa a seguir, os primeiros 6 encontros desta etapa, constituindo o Módulo 1, consistiram na realização de projetos de menor complexidade com o intuito de se familiarizarem com o manuseio dos componentes, se sentirem estimulados pela construção própria - ainda que orientada - de aparatos eletrônicos, e chamar a atenção para a necessidade de se aprender a sintaxe e lógica de uma linguagem de programação, uma vez que a interface do Arduino requer a construção de códigos que ditem como deve funcionar cada componente. A dinâmica de realização das atividades se desenrolou do seguinte modo: sendo divididos em quatro grupos de três, uma atividade era delegada a um desses grupos para que a preparassem durante a semana e a expusessem no sábado atendo-se aos menores detalhes concernentes à montagem do aparato, justificação dos códigos e ênfase nos conceitos físicos subjacentes, tudo isso após orientar os demais grupos a realizá-la quando para isso fossem solicitados.

Após isso, 5 encontros foram utilizados para o estudo de linguagem de programação C, todos incluídos no que se denominou Módulo 2. Por fim, os quatro encontros restantes, pertencentes ao Módulo 3, serviram para a proposição de projetos ligeiramente mais sofisticados que os anteriores, já pensando no trabalho final, na etapa de Aplicação dos conhecimentos, na qual deveriam desenvolver um projeto que apresentasse algum aspecto minimamente inovador.

A tabela 1 descreve as finalidades e os conceitos envolvidos em cada um dos projetos trabalhados nos encontros da presente etapa. É oportuno frisar que todas as ações em que houve manuseio de ideias tanto físicas quanto tecnológicas se direcionaram obedecendo a uma via de mão dupla: aqui, as TIC's são utilizadas de modo a oportunizar aprendizagem e consolidar conceitos associados à Física subjacente, da mesma forma que a solidez alcançada na compreensão destes propicia o entendimento dos mecanismos de funcionamento dos componentes eletrônicos. 
Tabela 1: Atividades desenvolvidas nos módulos 1, 2 e 3

\begin{tabular}{|c|c|c|}
\hline \multicolumn{3}{|c|}{ Módulo 1} \\
\hline Encontro & Finalidade do projeto & Conceitos realçados \\
\hline 2 & Fazer o botão acender um led quando acionado. & $\begin{array}{l}\text { Corrente, tensão e resistência, incitando-se o destaque à fun- } \\
\text { ção de cada um quando eram mencionados. }\end{array}$ \\
\hline 3 & $\begin{array}{l}\text { Enquanto expansão do anterior, neste projeto cada um } \\
\text { de três leds deveria ser acendido tão logo seu correspon- } \\
\text { dente botão fosse acionado. }\end{array}$ & Ressaltou-se o papel da associação em paralelo. \\
\hline 4 & $\begin{array}{l}\text { Construir um protótipo de piano rudimentar com três } \\
\text { notas musicais. }\end{array}$ & $\begin{array}{l}\text { Conceitos como tensão, corrente, resistência, associação em } \\
\text { paralelo e curto-circuito foram salientados durante as apre- } \\
\text { sentações. Além disso, a alteração das notas musicais medi- } \\
\text { ante a variação da frequência no código, e sua relação com a } \\
\text { corrente que passa pelo dispositivo, foi oportunamente dis- } \\
\text { cutida. }\end{array}$ \\
\hline 5 & $\begin{array}{l}\text { Montar um dispositivo que acione um sinal sonoro tão } \\
\text { logo a temperatura do ambiente exceda o limite imposto } \\
\text { pelo aluno. }\end{array}$ & $\begin{array}{l}\text { O conceito de temperatura foi explorado com maior realce, } \\
\text { sobretudo no tocante às conversões e correspondentes uni- } \\
\text { dades. }\end{array}$ \\
\hline 6 & $\begin{array}{l}\text { Construir um aparato que acenda o led em consonância } \\
\text { com parâmetros ligados à luminosidade ambiente. }\end{array}$ & $\begin{array}{l}\text { Propriedade manifestada por um resistor cuja resistência va- } \\
\text { ria em função da luz sobre ele incidente, além de levar em } \\
\text { conta associações em série e em paralelo, tensão e corrente. }\end{array}$ \\
\hline 7 & $\begin{array}{l}\text { Construir um dispositivo genérico que reproduza um } \\
\text { outro, projetado pelo professor, mostrado a eles em fun- } \\
\text { cionamento através de um vídeo. }\end{array}$ & $\begin{array}{l}\text { Realce ao papel crucial do entendimento de uma linguagem } \\
\text { de programação. O projeto, a despeito de sua simplicidade, } \\
\text { coloca ao aluno de maneira indisputável a necessidade de se } \\
\text { aprender a programar, pois exibe a ele um comportamento } \\
\text { e dele exige a escrita de um código que o sustenha. }\end{array}$ \\
\hline \multicolumn{3}{|c|}{ Módulo 2} \\
\hline 8 & Apresentação geral da linguagem de programação C. & Destaque à importância das linguagens de programação. \\
\hline 9 & $\begin{array}{l}\text { Aprender a declarar variáveis inteiras e decimais, e co- } \\
\text { mandos de entrada e saída. }\end{array}$ & Destaque à importância das linguagens de programação. \\
\hline 10 & $\begin{array}{l}\text { Promover a familiarização com os comandos condicio- } \\
\text { nais if e else. }\end{array}$ & Destaque à importância das linguagens de programação. \\
\hline 11 & $\begin{array}{l}\text { Aprender a trabalhar com caracteres e cadeias de carac- } \\
\text { teres (strings). }\end{array}$ & Destaque à importância das linguagens de programação. \\
\hline 12 & $\begin{array}{l}\text { Desenvolver um programa que, a partir de informações } \\
\text { sobre resistência, tensão e corrente, a potência elétrica } \\
\text { fosse obtida. }\end{array}$ & $\begin{array}{l}\text { Conceitos físicos de resistência, tensão, corrente e potência } \\
\text { elétrica, juntamente a uma consolidação da lógica de progra- } \\
\text { mação e sintaxe da linguagem C abordada. }\end{array}$ \\
\hline \multicolumn{3}{|c|}{ Módulo 3} \\
\hline 13 & Montar e programar um carrinho seguidor de linha. & $\begin{array}{l}\text { Conceitos relativos aos tipos de luz, em especial à sua com- } \\
\text { ponente infravermelha. }\end{array}$ \\
\hline 14 & Automatizar iluminação em tensão residencial (127V). & $\begin{array}{l}\text { Conceitos relacionados a alta e baixa tensão, bem como a } \\
\text { corrente contínua e alternada. }\end{array}$ \\
\hline 15 & $\begin{array}{l}\text { Acoplar um sensor de movimento a um sistema de de- } \\
\text { tecção. }\end{array}$ & $\begin{array}{l}\text { Conceitos associados à Física das Radiações, abordados na } \\
2^{a} \text { série do EM, foram retomados e reanalisados à luz do } \\
\text { dispositivo. }\end{array}$ \\
\hline 16 & Compreender o funcionamento do display LCD. & $\begin{array}{l}\text { Princípios de ligações básicas entre circuitos e cristais líqui- } \\
\text { dos. }\end{array}$ \\
\hline
\end{tabular}

A seguir são exibidas algumas fotos, nas Figuras 1, 2 e 3, registradas durante as atividades do curso. Pode se depreender das imagens, em razão da presença de grande número de computadores de mesa, que as atividades foram realizadas no interior de um laboratório de informática da escola; há que se dizer, no entanto, que apenas uns poucos estavam aptos para o uso.

A Figura 1 ilustra o trabalho em grupos por ocasião do desenvolvimento do projeto que tenciona acender um led premindo um botão, mediante interligação possibilitada pelo Arduino.

Por fim, a Figura 3 exibe a montagem, também em grupo, de circuito visando ao desenvolvimento de um piano rudimentar.

Por sua vez, a Figura 2 apresenta a explanação feita por um grupo aos demais sobre projeto de acionamento de três leds por intermédio de três botões. 


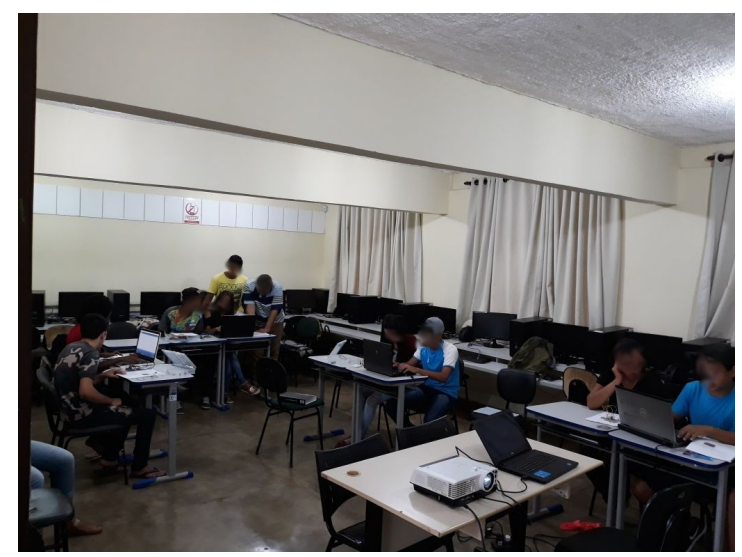

Figura 1: Realização de atividade no $2^{\circ}$ encontro.

\section{IV.1.3 Etapa 3: Aplicação dos conhecimentos}

Esta etapa foi concebida, dentro da estrutura dos 3MP's, como aquela em que os alunos deveriam lançar mão dos conhecimentos incorporados à sua estrutura cognitiva para a solução de outros novos para além daqueles propostos em caráter preliminar na primeira etapa.

Com efeito, a utilização de protoboards para o estabelecimento de ligações seriadas, paralelas e mistas, o funcionamento peculiar dos leds frente às lâmpadas convencionais, a utilização de sensores de luminosidade, de som e de fluxo hídrico acoplados a outros sistemas, assim como a automatização de processos os mais variados mediante a plataforma Arduino, foram razoavelmente dominados pelos discentes participantes.

Buscando-se, entretanto, grau maior de exigência e sofisticação, a fim de suscitar-lhes novas confrontações e, quem sabe, despertar um desejo adicional por continuar a aprender, a essa terceira etapa se incumbiu a tarefa de desenvolver projetos minimamente inovadores com o intento de serem apresentados na Feira de Ciências da escola.

Assim, os encontros $17^{\circ}, 18^{\circ}$ e $19^{\circ}$ foram todos eles empregados para os preparativos dos projetos finais necessários à integralização do curso, cujo desenvolvimento estava a ocorrer em paralelo com as últimas atividades realizadas. No $20^{\circ}$ encontro aconteceu a apresentação de todos eles, como se observa na Figura 4.

Embora todos os projetos tenham sido bem-sucedidos, atraindo para si a atenção da comunidade escolar por ocasião da apresentação na feira, um deles se destacou pelo alto grau de inovação. Batizado de Gerenciador Eletrônico de Consumo de Água, este dispositivo foi proposto como solução para um problema que aflige não apenas nossa região, mas quase todo o Brasil: o desperdício de água.

O princípio de funcionamento do dispositivo se baseia nas seguintes funções, efetuadas em sequência:

(a) Permite a inserção de uma cota inicial da água a ser consumida;

(b) Interrompe o fluxo quando a cota informada for atingida;

(c) Possibilita a liberação de água em quantidades previamente estabelecidas mediante a introdução de uma senha;

(d) Repete o processo acima sempre que o fluxo for interrompido. 


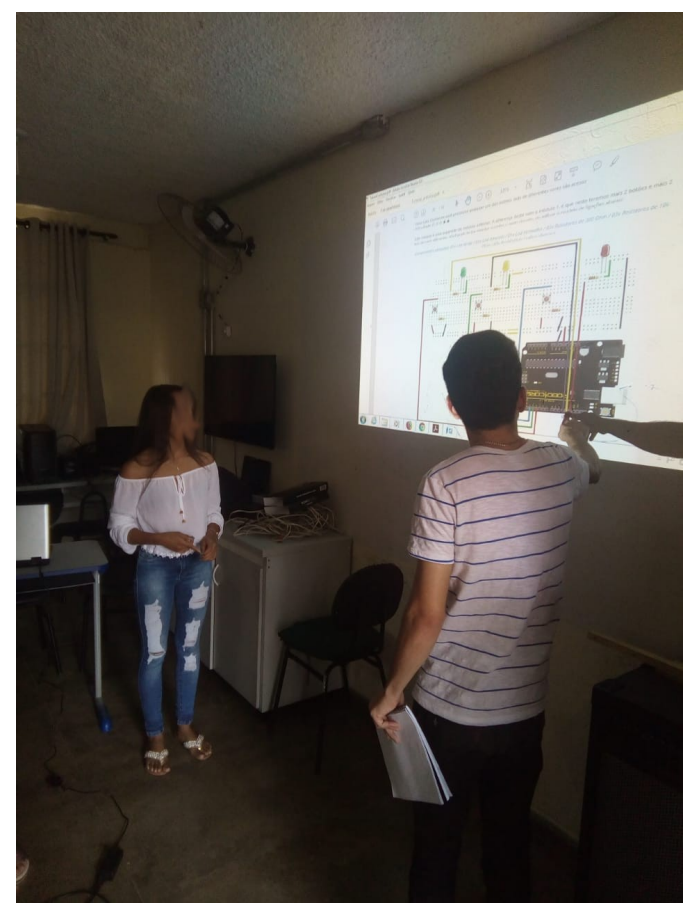

Figura 2: Apresentação de alunos no $3^{\circ}$ encontro.

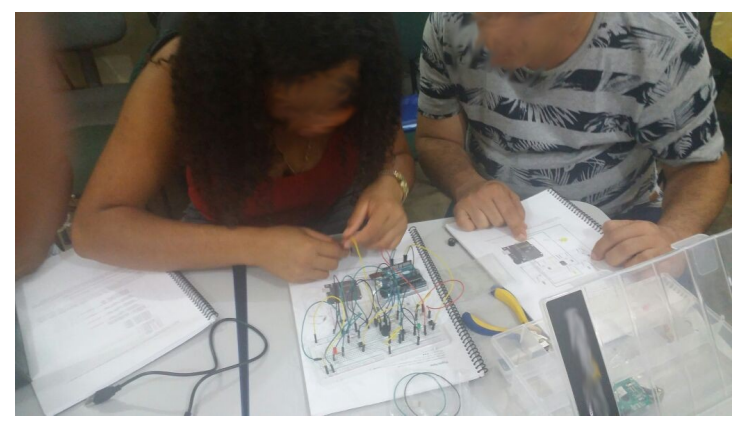

Figura 3: Realização de atividades no $4^{\circ}$ encontro.

A Figura 5 exibe duas fotos do dispositivo:

\section{Avaliação e Resultados}

Devido à sublime posição que ocupa dentro da prática pedagógica, não apenas enquanto mecanismo de verificação do aprendido pelos alunos, mas por oportunizar um momento de reflexão acerca dos instrumentos utilizados no processo de ensino-aprendizagem, a avaliação deve ser elaborada com bastante diligência para que tenha real sentido, e possa verdadeiramente fornecer os subsídios necessários à sua finalidade.

Em se tratando de recurso que possibilita a aferição da aprendizagem, antes de falar a respeito da composição da estrutura avaliativa, necessário se faz expor e discutir sobre o que é aprender com base em referenciais teóricos nos quais nos apoiamos, ligados à Ciência Cognitiva e à Teoria da Aprendizagem Significativa.

Em seu trabalho, Borges (1998) argumenta que aprender implica construir modelos 


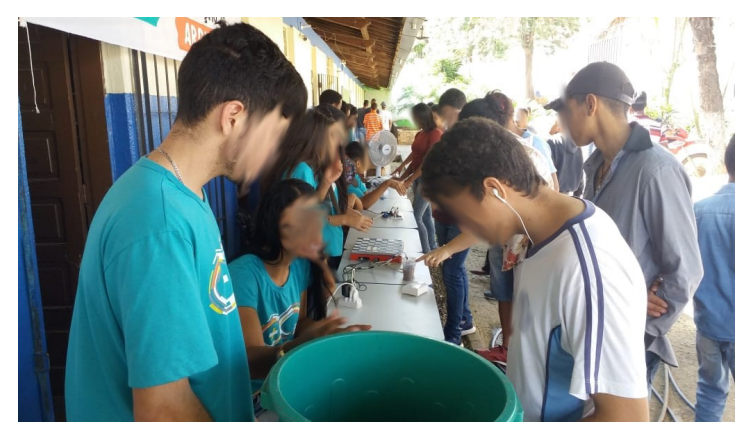

Figura 4: Apresentação dos projetos finais pelos alunos (blusas verdes) na Feira de Ciências realizada na escola.

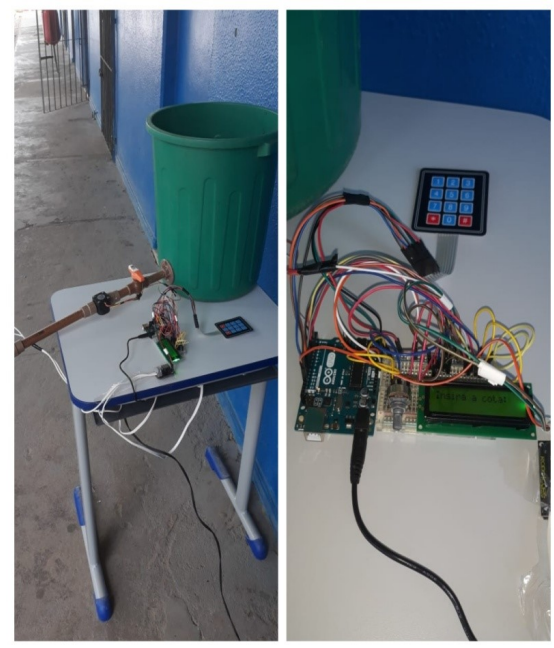

Figura 5: Dispositivo construído.

mentais cada vez mais produtivos, algo que advém com muito tempo e esforço da parte do aluno. Por essa razão as avaliações, muito mais que procurar pela presença de conhecimentos edificados em sua forma final, devem buscar por indícios de aprendizagem, uma vez que os modelos mentais, entendidos como estruturas imprescindíveis à compreensão, são construídos paulatinamente na estrutura cognitiva do aprendiz.

De modo similar, Moreira (2011) advoga a tese de que a avaliação da aprendizagem deve ser feita ao longo de sua implementação, buscando-se o que possa ser evidência de aprendizagem significativa, como captação de significados, compreensão, capacidade de explicar e de aplicar o conhecimento para a resolução de problemas.

Por tudo isso, as atividades avaliativas se dividiram em duas partes: 15 delas diluídas ao longo do curso, uma para cada dia da Etapa 2, destinada à aquisição de experiência e familiaridade com o funcionamento de sensores e demais dispositivos, além de noções básicas da linguagem de programação C; e o projeto final, para cuja arquitetura, embora não se exigisse completo ineditismo, requeria-se algum grau de inovação frente aos conhecidos pela comunidade que lida com eletrônica no Arduino.

De maneira sucinta, a distribuição de pontos ao longo do curso se regulou por quatro critérios, a saber, assiduidade, desempenho, compreensão e proatividade, contabilizados nas atividades realizadas no decorrer dos encontros e, separadamente, avaliadas no projeto final. Cada um desses critérios são entendidos e valorados conforme o que se expõe abaixo: 
- Assiduidade: considerando que o número de encontros, realizados em sábados não letivos, totalizaram 20, a presença em cada um deles correspondia a 5\% da nota relacionada a este critério. Entendemos ser este um aspecto importante dentro do contexto geral de avaliação porque contribui de maneira significativa para o despertar do engajamento e sentimento de pertencimento, tão delicados em um curso realizado uma vez por semana.

- Desempenho: aspecto relacionado à capacidade demonstrada pelo aluno em realizar as ligações dos sensores ao Arduino conforme ilustradas na apostila ou em outras fontes. Quando as atividades se referiam ao desenvolvimento de programas com linguagem C, o desempenho era analisado com base no êxito da escrita e operacionalização do código. Uma nota de 0 a 100 era atribuída a esse campo para cada atividade.

- Compreensão: associada à captação de significados e à capacidade de explicar e interrelacionar os conceitos físicos e procedimentos próprios da eletrônica. Aqui, de maneira mais subjetiva que no critério precedente, ao grau de compreensão era atribuída uma nota entre 0 e 100 para cada atividade.

- Proatividade: este campo está relacionado à postura assumida pelo aluno diante de uma tarefa: fazer apenas o que lhe foi pedido ou incrementar, ir além? Estimulando, por conseguinte, o aprendizado, uma nota entre 0 e 5 era conferida em acréscimo a cada atividade realizada.

Com o intuito de despertar motivação e, ao mesmo tempo, incutir seriedade para com um curso perpetrado fora dos trâmites oficiais, fora anunciado, desde seu início, que a escola concederia certificados aos alunos que obtivessem êxito ao término dos trabalhos, tão somente àqueles cujo aproveitamento fosse superior a 50\%. A nota final foi encontrada mediante uma média de todos os critérios, à exceção da proatividade, cuja média entrou como bônus.

No tocante ao projeto final, trabalho realizado em grupos de três alunos, seu valor correspondia a 50\% da nota no curso. Entende-se que tal valorização se justifica pela exigência de inovação, feita em maior ou menor grau, evidenciando uma aprendizagem significativa na medida em que vale-se de conhecimentos internalizados para propor a resolução de algum problema.

A Tabela 2 exibe as médias das notas alcançadas pelos alunos em cada um dos critérios de avaliação explicitados. 
Tabela 2: Médias das notas atribuídas a cada um dos alunos segundo os critérios avaliativos.

\begin{tabular}{|l|l|l|l|l|l|l|}
\hline Aluno & Frequência & Desempenho & Compreensão & $\begin{array}{l}\text { Resultado preliminar } \\
(\text { média aritmética })\end{array}$ & Proatividade & Resultado final \\
\hline A1 & $81,25 \%$ & $96,13 \%$ & $70,22 \%$ & $82,53 \%$ & 1,6 & $84,13 \%$ \\
\hline A2 & $100 \%$ & $94,37 \%$ & $81,45 \%$ & $91,94 \%$ & 1,8 & $93,74 \%$ \\
\hline A3 & $62,50 \%$ & $86,36 \%$ & $77,00 \%$ & $75,30 \%$ & 1,1 & $76,40 \%$ \\
\hline A4 & $100 \%$ & $74,16 \%$ & $59,16 \%$ & $77,77 \%$ & 0,8 & $77,85 \%$ \\
\hline A5 & $100 \%$ & $70,00 \%$ & $55,00 \%$ & $75,00 \%$ & 0,6 & $75,6 \%$ \\
\hline A6 & $81,25 \%$ & $74,16 \%$ & $56,66 \%$ & $70,69 \%$ & 0,8 & $71,49 \%$ \\
\hline A7 & $87,50 \%$ & $80,83 \%$ & $61,66 \%$ & $76,66 \%$ & 0,9 & $77,56 \%$ \\
\hline A8 & $87,50 \%$ & $80,83 \%$ & $61,66 \%$ & $76,66 \%$ & 0,9 & $77,56 \%$ \\
\hline A9 & $87,50 \%$ & $68,54 \%$ & $63,12 \%$ & $73,05 \%$ & 0,9 & $73,95 \%$ \\
\hline A10 & $100 \%$ & $67,50 \%$ & $54,16 \%$ & $73,89 \%$ & 1 & $74,89 \%$ \\
\hline A11 & $81,25 \%$ & $72,50 \%$ & $55,00 \%$ & $69,58 \%$ & 0,5 & $70,08 \%$ \\
\hline A12 & 87,50 & $74,37 \%$ & $63,12 \%$ & $75,00 \%$ & 0,9 & $75,90 \%$ \\
\hline
\end{tabular}

Analisando-se os dados expostos na Tabela 2 e procedendo a um balanço final de todo o caminho percorrido nessa longa e sinuosa estrada que é a aprendizagem, constatase, com base em escrutínio minucioso por via dos critérios acima listados, que todos os participantes lograram bons resultados nas avaliações processuais, assim como consolidaram muitos dos conceitos físicos aprendidos durante o Ensino Médio, especialmente aqueles que concomitantemente estavam estudando nas aulas regulares de Física.

Relevante é chamar a atenção para o fato de que a frequência nos encontros de todos os participantes ficou acima de $80 \%$, à exceção de um deles que, por motivos particulares sempre expostos de maneira muito clara a todos, apresentou índice de $62,5 \%$ nesse quesito.

\section{CONSIDERAÇÕES FINAIS}

Muitos são os trabalhos apresentando formas de uso de tecnologias de informação e comunicação (TIC's) como meios de agregar às maçantes aulas das mais variadas disciplinas na Educação Básica dinamismo, agilidade e recursos que possibilitem com maior facilidade estabelecer elos entre a bagagem sociocultural extraída das relações corriqueiras de modo intuitivo e irrefletido e o conhecimento científico apresentado na escola. O presente trabalho, porém, tencionou ir além, pois não buscou apenas utilizar as TIC's com tais propósitos, mas, seguindo recomendações explícitas na BNCC (BRASIL, 2017), instigou a criação de soluções tecnológicas ao ensejar uma compreensão mais sólida de princípios físicos por detrás do funcionamento de componentes eletrônicos.

Não obstante o fato de que as atividades tenham ocorrido dentro de um escopo complementar, sendo realizadas em dias não letivos, a dedicação e o empenho dispensados pelos alunos no correr do curso compensaram o tempo demandado para a execução do projeto, haja vista o substancial crescimento conceitual demonstrado por cada um deles.

Ponderando os objetivos iniciais, a forma como a sequência didática foi estruturada e os resultados obtidos, é de se considerar que tenha sido um trabalho digno de ser replicado em outros contextos em razão do alto potencial de engajar os alunos em atividades que aliam tecnologia, elemento ubíquo no cotidiano, a temas com os quais entram em contato na sala 
de aula por ocasião do estudo de Ciências Naturais.

\section{REFERÊNCIAS}

AUSUBEL, D. P. Educational psychology: A cognitive view. Holt, Rinehart and Winston New York, 1978.

BORGES, A. T. Modelos mentais de eletromagnetismo. Caderno Catarinense de Ensino de Física, Florianópolis, v. 15, n. 1, p. 7-31, 1998.

BRASIL. Base Nacional Comum Curricular (BNCC). Brasília: MEC. 2017. Disponível em: <http://basenacionalcomum.mec.gov.br/images/BNCC_EI_EF_110518_versaofinal_site.pdf> Acesso 27 de setembro de 2019.

DELIZOICOV, D. ANGOTTI, J. A. (1990). Física. São Paulo: Cortez.

LARA, A. L.; MANCIA, L. B.; SABCHUK, L.; PINTO, A. E. A.; SAKAGUTI, P. M. Y. ENSINO DE FÍSICA MEDIADO POR TECNOLOGIAS DE INFORMAÇÃO E COMUNICAÇÃO: UM RELATO DE EXPERIÊNCIA. XX Simpósio Nacional de Ensino de Física - SNEF 2013 - São Paulo, SP.

LYRA, D. G. Os três momentos pedagógicos no ensino de ciências na educação de jovens e adultos da rede pública de Goiânia, Goiás: o caso da dengue. 2013. 117p. Dissertação (Mestrado em Educação em Ciências e Matemáticas).Universidade Federal do Goiás, Goiânia.

MCROBERTS, M. Arduíno Básico. São Paulo: Novatec, 2011.

MOREIRA, M. A. Modelos Mentais. Investigações em Ensino de Ciências - V1(3), pp.193-232, 1996.

MOREIRA, M. A. Unidades de Enseñanza Potencialmente Significativas - UEPS. Aprendizagem Significativa em Revista. Porto Alegre. v. 1, n. 2, p. 43-63, 2011.

Subsídios teóricos para o professor pesquisador em ensino de ciências: A teoria da aprendizagem significativa. Instituto de Física, UFRGS, Porto Alegre, Brasil, 2009.

MUENCHEN, C.; DEMÉTRIO, D. Os três momentos pedagógicos e o contexto de produção do livro "Física". Ciência Educação, Bauru, v. 20, n. 3, 617-638, 2014

PIRES, M. A.; VEIT, E. A. Tecnologias de Informação e Comunicação para ampliar e motivar o aprendizado de Física no Ensino Médio. Revista Brasileira de Ensino de Física, v. 28, n. 2, p. $241-248,(2006)$. 
Revista do Professor de Física, v. 4, n. 2, p. 41-54, Brasília, 2020.

VERONEZ, D.; LUNKES, M.; MUCHENSKI, F.; VIZZOTTO, L. A Utilização das TICs no Ensino de Física para trabalhar conceitos de MRU e MRUV. Ensino \& Pesquisa, v. 13, n 1 (2015). 